\title{
RESPOSTAS AO TRÁFICO NO NORTE GLOBAL: O CASO DE PORTUGAL E ESPANHA
}

\author{
Responses to trafficking in the Global North: \\ The case of Portugal and Spain
}

Julie Lima de Pérez ${ }^{1}$

\begin{abstract}
Resumo. Países desenvolvidos usam ações e discursos contra o tráfico de seres humanos como uma maneira mais palatável de impor políticas que restringem a migração e o trabalho sexual. Ainda que suas metas e resultados sejam similares, a maneira como Estados individuais elaboram e utilizam suas estruturas antitráfico varia e gera consequentemente repercussões distintas. Podemos considerar, por exemplo, que ainda que as políticas Ibéricas sejam similares, a Espanha tem um sistema mais duramente criticado do que o de Portugal, pois seus métodos violam direitos de maneira mais clara.
\end{abstract}

Palavras-chave: tráfico de pessoas, migração, trabalho sexual, Espanha, Portugal.

\begin{abstract}
Developed countries use anti-trafficking actions and discourses as a more palatable way of imposing polices that restrict migration and sex work. Although their aims and results are similar, the way individual States elaborate and use their anti-trafficking frameworks differs and therefore leads to different repercussions. We may consider, for instance, that while Iberian policies are similar, Spain's system is much more harshly criticized than Portugal's as its methods violate rights in a clearer manner.
\end{abstract}

Keywords: human trafficking, migration, sex work, Spain, Portugal.

\section{Introdução}

O Protocolo de Palermo² é amplamente reconhecido como o mais relevante tratado internacional relacionado ao tráfico de seres humanos. Ações ligadas ao

1 Doutora em Criminologia pela Universidade de Gante/Bélgica. Niterói, RJ, Brasil.

2 Mais especificamente o "Protocolo Adicional à Convenção das Nações Unidas contra o Crime Organizado Transnacional Relativo à Prevenção, Repressão e Punição do Tráfico de Pessoas, em Especial Mulheres e Crianças", assinado no ano 2000. 
Protocolo devem, ao menos em teoria, se preocupar em resguardar os direitos fundamentais das vítimas, com especial atenção a mulheres e crianças. O Protocolo, no entanto, não é um instrumento de direitos humanos, mas um dos apêndices de uma convenção focada no crime transnacional ${ }^{3}$. Seu objetivo principal é, logo, a proteção da integridade territorial dos Estados partes e não da integridade física e moral de vítimas em potencial. Consequentemente, ainda que de maneira geral o discurso que envolve o combate ao tráfico humano seja imbuído de uma retórica humanitária, na prática ações antitráfico estatais frequentemente afetam negativamente aqueles que se comprometeram a proteger.

Nas últimas décadas o combate ao tráfico humano se tornou um tema central nas discussões globais. Ao contrário do que se afirma, isso não se deve exclusivamente a uma crescente preocupação com proteger segmentos vulneráveis da sociedade que estão à mercê de criminosos inescrupulosos. A alta disseminação da retórica antitráfico deve-se em grande parte ao fato desta ser uma maneira mais palatável de se implementar ações que restringem a migração e o trabalho sexual ${ }^{4}$.

A apropriação de instrumentos antitráfico para fins escusos não é um fenômeno recente, podendo traçar suas origens ao movimento do fim do século XIX contra a chamada "escravidão branca" ${ }^{5}$. Ainda que os debates das últimas décadas tenham pluralizado a discussão sobre tráfico humano incluindo, entre outros tipos, o tráfico laboral e para a remoção de órgãos - a tendência continua a ser o foco na "exploração sexual" (conceito este não definido) e a criação de agendas repressivas que afetam particularmente a mobilidade e a autonomia das mulheres. Exemplos de tais políticas podem ser encontrados na Europa ${ }^{6}$, nos Estados Unidos ${ }^{7}$ e no Canadá ${ }^{8}$. Nesse contexto é muito comum tratar as políticas antitráfico de países desenvolvidos como um grupo homogêneo; isso é particularmente recorrente ao se tratar de países membros da União Europeia.

Nas últimas décadas houve de fato uma progressiva "Europeização da política migratória" ${ }^{\prime \prime}$, particularmente no que se refere à implementação e

\footnotetext{
3 A Convenção das Nações Unidas contra o Crime Organizado Transnacional possui dois outros protocolos adicionais: o "Protocolo Relativo ao Combate ao Tráfico de Migrantes por vias Terrestre, Marítima e Aérea" e o "Protocolo Contra a Fabricação e o Tráfico llícito de Armas de Fogo, Suas Peças e Componentes e Munições".

4 BERMAN, Jacqueline. Biopolitical Management, Economic Calculation and "Trafficked Women"; CHAPKIS, Wendy. Trafficking, Migration, and the Law: Protecting Innocents, Punishing Immigrants.

5 DOEZEMA, Jo. Loose Women or Lost Women? The Re-emergence of the Myth of White Slavery in Contemporary Discourses of Trafficking in Women.

6 BERMAN, op. cit., p. 89.

CHAPKIS, op. cit., p. 294.

BROCK et alii. Migrant Sex Work: A Roundtable Analysis.

9 HUYSMANS, Jef. The European Union and the securization of migration, p. 756.
} 
execução de um maior controle das fronteiras ${ }^{10}$. No entanto, ainda que esses países tenham um mesmo objetivo geral - a contenção migratória - a maneira pela qual buscam atingir sua meta não é necessariamente a mesma. O uso de políticas antitráfico como instrumentos antimigratórios, ainda que recorrente, também varia. A definição nacional de tráfico, a posição do país com relação à prostituição e seu histórico com relação a questões migratórias são alguns dos fatores que afetam a maneira como a estrutura antitráfico de um país é construída e utilizada.

Esse artigo demonstrará que, apesar de terem objetivos e motivações muito similares, Portugal e Espanha conduzem e executam políticas e ações antitráfico de maneiras diferentes. Essas abordagens distintas, por sua vez, levam a diferentes repercussões para ações que são em essência similares e geram resultados parecidos.

\section{A agenda de oposição à migração e ao trabalho sexual}

Países desenvolvidos tendem a manipular definições, políticas, estatísticas e ações antitráfico para melhor servir seus objetivos, ainda que isso traga efeitos nocivos a migrantes, sejam eles vítimas de tráfico ou não ${ }^{11}$. Tais objetivos podem ser divididos em duas categorias altamente interligadas: antimigração e antitrabalho sexual.

\section{a. Antimigração}

A perseguição a imigrantes e a vontade de limitar e controlar seus movimentos são tendências recorrentes nos períodos de crises econômicas, políticas e sociais ${ }^{12}$. Tais ações fazem parte de uma tendência histórica a culpabilizar grupos marginalizados pelos problemas enfrentados pelos grupos dominantes - vide a trajetória secular do antisemitismo e antizinganismo na Europa.

Na Europa contemporânea - de fato, na grande parte dos países desenvolvidos - há uma ascensão de políticas que levam à criminalização de violações das leis migratórias e à imposição de consequências migratórias para atos criminais ${ }^{13}$. Nesse contexto, aqueles que são detidos devido a questões administrativas ligadas à migração muitas vezes são submetidos a condições parecidas ou até piores do que aquelas impostas aos que são condenados por

\footnotetext{
${ }_{10}$ MITSILEGAS, Valsamis. Immigration Control in an Era of Globalization: Deflecting Foreigners, Weakening Citizens, and Strengthening the State, p. 4.

11 LIMA DE PÉREZ, Julie. Labelling migrants who sell sex: A case study of Brazilians in Spain and Portugal.

${ }^{12}$ PARKIN, Joanna. The Criminalisation of Migration in Europe: A State-of-the-Art of the Academic Literature and Research, p. 4.

${ }^{13}$ STUMPF, Juliet P. The justice of crimmigration law and the security of home.
} 
crimes. Agravando mais a situação, migrantes detidos nessas condições não se beneficiam das medidas de salvaguarda que existem no sistema judiciário ${ }^{14}$.

Esta atual visão crimigratória afeta a estrutura antitráfico de países considerados primariamente como receptores. Na prática, ainda que possuam uma retórica mais ligada aos direitos humanos, os objetivos, métodos e principalmente resultados das ações antitráfico são os mesmos que os das ações de controle de migração ${ }^{15}$. Isso fica bem claro ao analisarmos como as políticas centradas nos três "Ps" - prevenção, proteção e punição - são conduzidas.

Ações de prevenção são supostamente baseadas na ideia de que é preciso alertar as pessoas (principalmente aquelas oriundas de países em desenvolvimento) sobre o tráfico humano para que elas possam tomar decisões de forma consciente sobre projetos migratórios. Algumas ações conseguem, de fato, disseminar informações de maneira clara e objetiva, inclusive provendo orientações sobre o que uma pessoa deve fazer caso se encontre em uma situação de exploração. Grande parte da propaganda antitráfico contemporânea, no entanto, tende a se basear em "táticas do medo".

Países receptores frequentemente lançam ou apoiam (inclusive financeiramente) campanhas que visam "alertar" migrantes em potencial sobre os riscos de empreender uma jornada não sancionada. Com afirmações como "você não vai trabalhar no exterior, vai para ser escravizada" e imagens de mulheres enjauladas, fica claro que o intuito de governos e instituições é na realidade assustar o seu público-alvo. A ideia a ser passada é que as pessoas estarão mais seguras caso não abandonem o seu país, pois o risco de serem explorados no exterior é grande ${ }^{16}$.

Há dois grandes problemas com essa noção. O primeiro é que a ideia de que o país de origem é um local seguro é, muitas vezes, claramente falsa ${ }^{17}$ Muitas pessoas veem a migração justamente como uma maneira de escapar da violência física e estrutural na qual vivem. Essa situação de violência é, por vezes, tão contundente que muito migrantes consideram que melhoraram suas vidas mesmo passando por situações de exploração no exterior ${ }^{18}$.

O segundo é que a experiência migratória é, muitas vezes, perigosa não devido às ações de criminosos, mas sim porque os Estados receptores a construíram deliberadamente desse modo, negando a migrantes (não documentados) acesso a serviços importantes e direitos básicos, deixando-os

\footnotetext{
${ }^{14}$ MAJCHER, Izabella. "Crimmigration" in the European Union through the Lens of Immigration Detention, p. 17.

15 BERMAN, op. cit., p. 89.

${ }^{16}$ LIMA DE PÉREZ, Julie. Analysing the use of the trafficking victim archetype by Brazil and the Iberian countries.

17 SHARMA, Nandita. Travel Agency: A Critique of Anti-Trafficking Campaigns, p. 54.

${ }^{18}$ PISCITELLI, Adriana. Sujeição ou Subversão: Migrantes Brasileiras na Indústria do Sexo na Espanha.
} 
vulneráveis à exploração, principalmente no mercado de trabalho ${ }^{19}$. A hipótese de que os países receptores patrocinem campanhas de prevenção por estarem preocupados com o que acontecerá com os migrantes é então insustentável.

De maneira similar, a ideia de que as ações de proteção são construídas em benefício às potenciais vítimas também é altamente problemática. Isso fica particularmente claro se considerarmos duas das suas vertentes mais comuns em países desenvolvidos: a "proteção por negação de entrada" e as "operações de resgate".

A "proteção por negação de entrada" consiste em recusar migrantes nas fronteiras (ainda que eles preencham todos os pré-requisitos para ingressar no país) quando se suspeita que eles sejam vítimas de tráfico, supostamente evitando que eles sejam explorados. O problema é que essa "suspeita" é baseada quase que exclusivamente em informações visuais ou, no máximo, em conversas que duram poucos minutos. O "perfil" de pessoas potencialmente traficadas utilizado nessa avaliação tende a estar imbuído em ideias racistas, sexistas, classistas e xenófobas sobre quem tem o direito e a capacidade de migrar. Não há qualquer preocupação com dívidas já assumidas ou com o fato de que há uma alta possibilidade desses migrantes tentarem uma nova jornada, acarretando maiores custos e provavelmente utilizando rotas mais perigosas.

As "ações de resgate" consistem em batidas policiais em locais onde ocorre prostituição. Nelas "vítimas de tráfico" (quase que exclusivamente estrangeiras indocumentadas) são retiradas, por vezes à força, pela polícia, sem que se considere a sua opinião sobre a situação em que se encontram. O seu "resgate" é frequentemente seguido de uma ação de deportação. Às vezes, essa deportação é precedida pela detenção da migrante em um centro de estrangeiros por semanas ou até meses sem que ela tenha cometido qualquer tipo de crime.

Nos poucos casos em que às vítimas realmente é oferecida alguma proteção, esta tende a ser altamente condicional; a maioria dos Estados Membros da União Europeia só oferece um auxílio abrangente àquelas que tem um valor jurídico no caso legal contra seus traficantes ${ }^{20}$. Nesse contexto, o foco no terceiro " $\mathrm{P}$ " - punição - claramente suplanta a preocupação com a proteção às vítimas, já que essa política ignora os diversos motivos - incluindo medo de retaliações e a dificuldade em se reviver o trauma da exploração que podem levar uma vítima a se recusar a cooperar com as autoridades.

\section{b. Antitrabalho sexual}

A exploração sexual ainda é o foco principal - quando não exclusivo - da grande maioria das ações antitráfico em países desenvolvidos. Isso se deve em

\footnotetext{
19 SHARMA, op. cit., p. 56-57.

${ }^{20}$ MITSILEGAS, op. cit., p. 8.
} 
parte ao fato de existir uma dualidade clara na maneira como casos de tráfico são classificados. Situações migratórias que envolvem homens em um contexto laboral são frequentemente classificadas como casos de migração irregular, independente das condições de migração e de se houve ou não exploração. A migração autônoma feminina, ao contrário, é frequentemente classificada como tráfico, principalmente se ocorre no contexto da indústria do sexo. Mesmo quando não existem indícios de fraude, coerção ou exploração (a não ser na visão daqueles que creem que todo trabalho sexual é inerentemente uma forma de exploração), a capacidade de autodeterminação das migrantes que vendem sexo é questionada e neutralizada ${ }^{21}$.

A retórica antitráfico frequentemente tem um cunho moralista e centra-se na degradação inerente na exploração sexual. No entanto, a percepção do que é "exploração sexual" é muitas vezes limitada a uma concepção de exploração sexual comercial que envolve quase que exclusivamente migrantes, já que estas são consideradas como inerentemente "vulneráveis".

A questão, no entanto, vai além da moralidade. O movimento antiprostituição no contexto de tráfico muitas vezes reflete também um medo da invasão de migrantes, com todas as implicações que esses sentimentos antimigratórios acarretam. Kulick ${ }^{22}$ argumenta, por exemplo, que, ao invés de se basear somente nos mais impolutos ideais de paridade de gênero como é frequentemente alardeado, o modelo sueco de prostituição (que pune a demanda e a "exploração" por terceiras partes) foi criado em grande parte em resposta à (então possível) entrada do país na União Europeia. A luta contra a prostituição (estrangeira) - que foi associada ao crime organizado, drogas e doenças - foi uma maneira "aceitável" de externalizar os medos suecos relacionados a uma possível "invasão" de migrantes do Leste Europeu.

\section{A abordagem antitráfico na Espanha}

A Espanha por muitos anos pareceu relutar a adaptar suas leis aos standards internacionais estabelecidos pelas Nações Unidas, pelo Conselho da Europa e pela União Europeia, temendo, talvez, que estes a impedissem de manipular a sua estrutura antitráfico para melhor servir aos seus objetivos. Sua legislação só passou a reconhecer todos os tipos de tráfico após o país ter sido condenado pelo Tribunal de Justiça da União Europeia (Caso C-266/08) pela não transposição da Diretiva de 2004 sobre a residência de vítimas de

${ }^{21}$ BLANCHET, Thérèse. Beyond Boundaries - A Critical Look at Women Labour Migration and the Trafficking Within, p. 4-5; FRISSO, Giovanna Maria. O processo de tipificação do tráfico internacional de pessoas e a contínua negação da autonomia da mulher migrante pelo direito brasileiro, p. 76.

${ }^{22}$ KULICK, Don. Sex in the new Europe: The criminalization of clients and Swedish fear of penetration. 
tráfico ${ }^{23}$. Mesmo após essa mudança a Espanha continua lidando quase que exclusivamente com tráfico para a exploração sexual.

O país utiliza uma abordagem primariamente policial e de crimigração, onde a segurança de suas fronteiras e a prisão e condenação de traficantes são os objetivos primários, frequentemente alcançados à custa do bem estar e dos direitos das vítimas de tráfico e outros migrantes. Isso fica claro quando consideramos as ações de proteção mais comuns no país - a negação de entrada ao território nacional e as "operações de resgate" - e a maneira como elas são conduzidas.

A intensificação dos controles fronteiriços é destacada pelo governo como um dos componentes chaves da sua luta contra o tráfico para exploração sexual ${ }^{24}$. A base dessa política é a suposta crença de que quanto menos migrantes irregulares chegarem ao país, menos vítimas de tráfico estarão presentes na Espanha. Essa lógica ignora, é claro, que nem todas as vítimas de tráfico e exploração estão indocumentadas. Além disso, o processo de "identificação" nas fronteiras parece se basear quase que exclusivamente no uso de perfis de risco que tendem a se focar desproporcionalmente em mulheres, pessoas não brancas e aqueles que não aparentam pertencerem a classes mais abastadas. Presume-se - sem que haja evidência concreta para isso - que esses são os grupos mais vulneráveis à exploração.

As "operações de resgate" são similarmente problemáticas. A ênfase em se resgatar vítimas de tráfico que estão sendo exploradas sexualmente de forma comercial é explicada em parte pela forte condenação moral da prostituição que existe no país, apesar da atividade em si ser lícita. No entanto, essa "preocupação" atinge quase que exclusivamente mulheres estrangeiras advindas de países em desenvolvimento ${ }^{25}$ - prostitutas espanholas e comunitárias (com algumas exceções) raramente são consideradas como potenciais vítimas pelas forças de segurança do Estado ${ }^{26}$.

${ }^{23}$ Diretiva 2004/81/CE do Conselho, de 29 de Abril de 2004, relativa ao título de residência concedido aos nacionais de países terceiros que sejam vítimas do tráfico de seres humanos ou objeto de uma ação de auxílio à imigração ilegal, e que cooperem com as autoridades competentes (GRETA. Report concerning the implementation of the Council of Europe Convention on Action against Trafficking in Human Beings by Spain).

${ }^{24}$ FERNÁNDEZ DÍAZ, Jorge. Intervención del Ministro del Interior, Jorge Fernández Díaz, en la Presentación del Plan Policial de Lucha contra la Trata de Seres Humanos con Fines de Explotación Sexual.

${ }^{25}$ A Guarda Civil Espanhola considera que toda mulher estrangeira atuando na prostituição é uma vítima de tráfico (em potencial). Nas palavras de um de seus relatórios, considera-se "...como 'vítimas em potencial' as pessoas (a maioria delas mulheres) que exercem a prostituição [em clubes] por entender que o fazem sem nenhum amparo administrativo, por encontrar-se em um estado de necessidade (ainda que não todas) e porque, denunciando ou não [uma situação de tráfico/exploração], sempre fica a dúvida sobre se exercem essa atividade baixo o controle mais ou menos rigoroso de pessoas e organizações dedicadas a atividades criminosas" (GUARDIA CIVIL. Informe Criminológico - Tráfico de seres humanos 2005, p. 12).

${ }^{26}$ No entanto, dados da Guarda Civil mostram que em diversos anos a porcentagem de espanholas 
Pela legislação espanhola em vigor, casos onde existem indícios de tráfico deveriam ser investigados e as vítimas em potencial deveriam receber o suporte necessário. Isso, no entanto, não é o que ocorre. Quando uma trabalhadora sexual é descoberta em uma situação irregular, ela é detida pela polícia, ainda que não tenha cometido nenhuma infração criminal. Em alguns casos ela é advertida com uma notificação de expulsão do país. Em outros sua autonomia é restrita de imediato. Por vezes ela é deportada pelo governo espanhol após ter sido detida por um espaço de tempo relativamente curto; quando tem menos sorte é remanejada para um centro de detenção de estrangeiros onde ficará encarcerada (às vezes por meses a fio) até que seu retorno ao país de origem possa ser coordenado. Em ambos os casos a situação individual de cada mulher é raramente considerada e seus direitos muitas vezes violados ${ }^{27}$.

Assim, apesar da retórica que afirma que ações de proteção visam primariamente assegurar a segurança e o bem estar das vítimas em potencial, a realidade é bem diferente. Isso fica muito claro ao se observar a maneira como tais ações são descritas por jornalistas. O artigo "Espanha prende quadrilha que oferecia 'milhagem' a clientes de prostitutas" 28 , por exemplo, afirma que de "acordo com informações do Ministério do Interior espanhol, as mulheres [resgatadas] viviam em cárcere privado e eram forçadas a estar disponíveis para os clientes 24 horas por dia", demonstrando uma clara intenção do governo de sensibilizar o público com a situação dessas mulheres. Três parágrafos depois, no entanto, o artigo avisa que "as prostitutas" que tanto foram exploradas "já receberam ordens de deportação por estadia ilegal na Espanha". O mesmo governo que justifica a disseminação em massa de tais operações com o resgate das vítimas não tem nenhum desejo de ajudá-las após a sua identificação.

Além dos problemas inerentes às operações em si, existe também um alto número de denúncias e reclamações feitas por indivíduos e ONGs sobre o tratamento dado a migrantes detidos nas fronteiras e dentro do território espanhol. O tratamento recebido por migrantes - que incluem prostitutas "resgatadas" contra a sua vontade de locais onde trabalhavam e vítimas de tráfico que não receberam nenhum tipo de proteção estatal - nos centros de detenção de estrangeiros chega ao extremo de envolver gravíssimas violações de direitos humanos, incluindo violência sexual ${ }^{29}$.

que denunciaram serem vítimas de tráfico e/ou exploração na indústria do sexo foi maior que a porcentagem de estrangeiras que fez o mesmo (LIMA DE PÉREZ, Julie. Examining trafficking statistics regarding Brazilian victims in Spain and Portugal).

${ }^{27}$ PISCITELLI, op. cit.

${ }^{28}$ Cf. <http://www.bbc.co.uk/portuguese/noticias/2011/05/110525_policia_prostituicao_fidelida de_af.shtml $>$.

${ }^{29}$ PISCITELLI, op. cit.; WOMEN'S LINK WORLDWIDE. Mujeres en los centros de internamiento de extranjeros (CIE): realidades entre rejas. 
$\mathrm{Na}$ prática as ações de proteção aparentam ser designadas não para proteger as vítimas em potencial, mas sim para proteger o Estado delas. Essa repulsa a certos tipos de migrantes parece ser baseada principalmente em ideias pervasivas em diversos países desenvolvidos sobre os impactos negativos da migração que parecem ter se tornado ainda mais abrangentes desde o começo da crise econômica mundial em 2008. A maior parte da retórica antimigratória não faz sentido e tem pouca relação com a realidade, sendo muito mais ligada ao aumento da xenofobia e do racismo em resposta a problemas econômicos, sociais e políticos ${ }^{30}$.

\section{A abordagem antitráfico em Portugal}

Assim como ocorreu em outros países europeus, o uso contemporâneo de uma retórica alarmista sobre o tráfico humano foi uma peça essencial na criação e legitimação das estritas políticas migratórias portuguesas em voga na atualidade $^{31}$. No entanto, ainda que seu maior objetivo seja o mesmo que é atribuído à grande maioria dos países desenvolvidos - resguardar seu território de migrantes indesejados, particularmente se estes estão associados à indústria do sexo -, a maneira com que Portugal vem utilizando suas estruturas antitráfico difere em alguns pontos do que acontece no território do país vizinho.

Portugal modificou sua legislação antitráfico em 2007, passando a focar mais na exploração laboral, o que justificou a proliferação extensa de inspeções que levam à identificação e expulsão de migrantes irregulares em uma grande variedade de setores ${ }^{32}$. O país, no entanto, não abriu mão de continuar a conduzir "inspeções" no âmbito da indústria do sexo. Ainda que tais ações sejam comuns em diversos países receptores, é a maneira pela qual ele as conduz que o diferencia da maioria de outros países que usam a mesma tática.

Ao contrário do que ocorre na Espanha, em Portugal tais operações não partem da premissa que todas as mulheres (estrangeiras) exercendo a prostituição são (potenciais) vítimas de tráfico. Ao contrário, há um reconhecimento de que essas mulheres (muitas delas brasileiras) são em sua grande maioria trabalhadoras independentes e que entre elas há um número comparativamente pequeno de vítimas. No entanto, a posição antiprostituição (e antiprostitutas) que existe em Portugal, aliada à percepção negativa sobre mulheres brasileiras criou uma

\footnotetext{
${ }^{30}$ WEBER, Serge. D'un Rideau de Fer à L'Autre: Schengen et la Discrimination dans I'Accès à la Mobilité Migratoire.

${ }^{31}$ CHRISTOFOlETTI TOGNI, Paula, ALVIM, Filipa. Sob o véu dos direitos humanos: Tráfico, Tráfego e Políticas Públicas para a Imigração. Um estudo de caso sobre as mulheres brasileiras em Portugal, p. 148.

32 Tal mudança de foco comprovou que, ao contrário do que afirmava a retórica pré-2007, o tráfico laboral em Portugal tem dimensões tão significativas - e potencialmente até mesmo maiores quanto às do tráfico sexual (LIMA DE PÉREZ, Julie. A criminological reading of the concept of vulnerability: A case study of Brazilian trafficking victims).
} 
impressão prevalente, ainda que não universal, de que essas trabalhadoras sexuais "autônomas" vão até Portugal para "ganhar dinheiro fácil" à custa da integridade moral e econômica das famílias portuguesas ${ }^{33}$.

Criou-se então um sistema supostamente meritocrático que se baseia em uma clara distinção entre um grande número de migrantes "maus" (neste caso, trabalhadoras sexuais vistas como independentes) que merecem ser punidos com a expulsão e um pequeno e seleto grupo de migrantes "bons" (neste caso, vítimas de tráfico legitimadas pelo Estado) que merecem um mínimo de proteção e suporte ${ }^{34}$. Assim, Portugal faz uso do alto nível de estigma que existe contra mulheres que trabalham na indústria do sexo para justificar a expulsão de dezenas de migrantes irregulares para cada "vítima" em potencial encontrada.

O sistema protecionista português também faz uso de ações da negação de entrada baseado em perfis considerados de "risco." Assim como acontece com as inspeções em território português, tais ações tendem a trazer relativamente pouca repercussão negativa, apesar de seus problemas inerentes. Isso não significa que o sistema português seja imune a casos de abuso ou corrupção. Há, no entanto, ao menos aparentemente, um mínimo de preocupação em respeitar os direitos humanos dos migrantes detidos nas fronteiras portuguesas e durante inspeções policiais, e daqueles que se encontram no único centro de detenção de longo prazo que existe no país ${ }^{35}$.

Essa "preocupação" consiste, na realidade, na abstenção da violação severa, consistente e rotineira dos direitos e da dignidade dos migrantes detidos e barrados. Esse "respeito" não é abrangente, já que não garante aos migrantes acesso a todos os seus direitos, ou mesmo universal, pois existem abusos pontuais. Mesmo assim, a maneira como essas ações são conduzidas levam a uma repercussão internacional muito menor e menos crítica do que aquela recebida por países onde o tratamento de migrantes é explicitamente e rotineiramente mais truculento.

\section{Conclusão}

Ainda que exista uma tendência a se considerar as políticas de tráfico de países desenvolvidos como monolíticas, já que seus objetivos e resultados são similares, essa não é bem a realidade. Alguns Estados levam a abordagem crimigratória ao extremo, expondo migrantes não só a uma atmosfera carcerária, mas a um ambiente que também é explorador, danoso e, logo, altamente criticado. Outros já têm uma posição menos radical ou ao menos mais sutil e

\footnotetext{
33 Ibidem; MACHADO PAIS, José. Mothers, whores and spells: Tradition and change in Portuguese sexuality.

${ }^{34}$ LIMA DE PÉREZ, Labelling migrants..., op. cit.

35 PROVEDOR DE JUSTIÇA. A instalação temporária de cidadãos estrangeiros não admitidos em Portugal ou em processo de afastamento do território nacional.
} 
conseguem assim atingir seus objetivos (barrar e/ou expulsar certos migrantes) sem atrair muita atenção ou repercussões negativas.

Em termos essenciais as políticas portuguesas e espanholas - números significativos de recusas de entrada nas fronteiras aéreas baseadas somente em perfis problemáticos, uma grande quantidade de inspeções que resultam na detenção e expulsão de dezenas de migrantes que vendem sexo no país - são as mesmas. A percepção e a repercussão de tais políticas, no entanto, é bem distinta. Isso fica claro, por exemplo, quando se compara a relação do Brasil com ambos os países.

O Brasil é reconhecido internacionalmente como uma grande fonte de vítimas de tráfico e são muito comuns as afirmações de que a Península Ibérica é um dos maiores, se não o maior, destino de vítimas de tráfico brasileiras e de brasileiros que trabalham na indústria do $\operatorname{sexo}^{36}$. Não é surpresa, então, constatar que tanto Portugal quanto Espanha impedem que um grande número de brasileiros entre em seus territórios todos os anos.

O tratamento e as instalações oferecidos a brasileiros em aeroportos espanhóisé muitas vezes considerado truculento, desproporcional e inadequado, gerando grande atenção negativa da mídia brasileira e transformando-se por diversas vezes em uma questão diplomática de alto escalão entre os dois países. Já Portugal, ao adotar em anos recentes uma maneira mais cautelosa de lidar com migrantes e oferecendo a eles instalação e tratamento de melhor qualidade, conseguiu que as suas ações fossem muito menos discutidas e criticadas no Brasil ainda que o país continue a barrar brasileiros em larga escala ${ }^{37}$.

Países desenvolvidos procuram usar ações e discursos contra o tráfico de seres humanos como uma maneira mais palatável de impor políticas que restringem a migração e o trabalho sexual. Tal uso, no entanto, precisa ser plausível para que seja feito com sucesso. Países que montam estruturas antitráfico dentro de um sistema explicitamente crimigratório e violento não conseguem sustentar a sua retórica protecionista. Já aqueles que manipulam suas estruturas e políticas antitráfico de maneira mais sutil e com menores indícios de exploração conseguem não só receber menos críticas por parte da sociedade civil e da comunidade internacional, mas também recebem um maior apoio por parte da sua própria população para alcançar seus objetivos.

\footnotetext{
${ }^{36}$ LIMA DE PÉREZ, Labelling migrants..., op. cit.

37 Ibidem. Ainda que a Espanha barre anualmente um número muito superior de migrantes do que Portugal, dados da Eurostat (cf. <http://ec.europa.eu/eurostat $>$ ) demonstram que essa disparidade é relativamente pequena quando se considera a quantidade de brasileiros que tem a entrada negada nas fronteiras aéreas e logo não justifica a disparidade da repercussão no Brasil sobre as ações de ambos os países.
} 


\section{Bibliografia}

BERMAN, Jacqueline. Biopolitical Management, Economic Calculation and "Trafficked Women". International Migration, v. 48, n. 4, 2010, p. 84-113.

BLANCHET, Thérèse. Beyond Boundaries - A Critical Look at Women Labour Migration and the Trafficking Within. Dhaka: USAID, 2012.

BROCK, Deborah; GILLIES, Kara; OLIVER, Chantelle; SUTDHIBHASILP, Mook. Migrant Sex Work: A Roundtable Analysis. Canadian Woman Studies, v. 20, n. 2, 2000, p. 84-91.

CHAPKIS, Wendy. Trafficking, Migration, and the Law: Protecting Innocents, Punishing Immigrants. Gender \& Society, v. 17, n. 6, 2003, p. 923-937.

CHRISTOFOLETTI TOGNI, Paula; ALVIM, Filipa. Sob o véu dos direitos humanos: Tráfico, Tráfego e Políticas Públicas para a Imigração. Um estudo de caso sobre as mulheres brasileiras em Portugal. In CARVALHO, Flávio; BADET SOUZA, Maria; CALLOU, Manuella; RUBIRALTA, Mar (eds.). Atas do $1^{\circ}$ Seminário de Estudos sobre Imigração Brasileira na Europa. Barcelona: Universitat de Barcelona, 2010, p. 145-152.

DOEZEMA, Jo. Loose Women or Lost Women? The Re-emergence of the Myth of White Slavery in Contemporary Discourses of Trafficking in Women. Gender Issues, Winter, 2000, p. 23-50.

FERNÁNDEZ DÍAZ, Jorge. Intervención del Ministro del Interior, Jorge Fernández Díaz, en la Presentación del Plan Policial de Lucha contra la Trata de Seres Humanos con Fines de Explotación Sexual. Disponível em: < http://www.policia. es/prensa/20130417_2.html>. Acesso em: 27.05.2013.

FRISSO, Giovanna Maria. O processo de tipificação do tráfico internacional de pessoas e a contínua negação da autonomia da mulher migrante pelo direito brasileiro. In Secretaria Nacional de Justiça; UNODC (orgs.). Cadernos Temáticos sobre Tráfico de Pessoas. Volume 2: Migração e Tráfico de Pessoas. Brasília: Ministério da Justiça, 2014, p. 60-85.

GROUP OF EXPERTS ON ACTION AGAINST TRAFFICKING IN HUMAN BEINGS [GRETA]. Report concerning the implementation of the Council of Europe Convention on Action against Trafficking in Human Beings by Spain. Strasbourg: Council of Europe, 2013.

GUARDIA CIVIL. Informe Criminológico - Tráfico de seres humanos 2005. Madrid: Departamento de Análisis Criminal de la Unidad Técnica de Policía Judicial de la Guardia Civil, 2005.

HUYSMANS, Jef. The European Union and the securization of migration. Journal of Common Market Studies, v. 38, n. 5, 2000, p. 751-777.

KULICK, Don. Sex in the new Europe: The criminalization of clients and Swedish fear of penetration. Anthropological Theory, v. 3, n. 2, 2003, p. 199-218.

LIMA DE PÉREZ, Julie. Analysing the use of the trafficking victim archetype by Brazil and the Iberian countries. In PERSAK, Nina; VERMEULEN, Gert (eds.). Reframing Prostitution: From Discourse to Description, from Moralisation to Normalisation? Antwerp: Maklu, 2014, p. 173-198. 
LIMA DE PÉREZ, Julie. A criminological reading of the concept of vulnerability: A case study of Brazilian trafficking victims. Social \& Legal Studies, 2015.

LIMA DE PÉREZ, Julie. Examining trafficking statistics regarding Brazilian victims in Spain and Portugal. Crime, Law and Social Change, v. 63, n. 3, 2015, p. 159-190.

LIMA DE PÉREZ, Julie. Labelling migrants who sell sex: A case study of Brazilians in Spain and Portugal. Antwerp: Maklu, 2015.

MACHADO PAIS, José. Mothers, whores and spells: Tradition and change in Portuguese sexuality. Ethnography, v. 12, n. 4, 2011, p. 445-465.

MAJCHER, Izabella. "Crimmigration" in the European Union through the Lens of Immigration Detention. Global Detention Project Working Paper, n. 6, 2013. Disponível em: <http://ssrn.com/abstract=2340566>. Acesso em: 03.03.2014.

MITSILEGAS, Valsamis. Immigration Control in an Era of Globalization: Deflecting Foreigners, Weakening Citizens, and Strengthening the State. Indiana Journal of Global Legal Studies, v. 19, n. 1, 2012, p. 3-60.

PARKIN, Joanna. The Criminalisation of Migration in Europe: A State-of-the-Art of the Academic Literature and Research. CEPS Papers in Liberty and Security in Europe, 6, 2013. Disponível em: < http://ssrn.com/abstract=2350119>. Acesso em: 04.03.2014.

PISCITELLI, Adriana. Sujeição ou Subversão: Migrantes Brasileiras na Indústria do Sexo na Espanha. História e Perspectivas, v. 35, 2006, p. 13-55.

PROVEDOR DE JUSTIÇA. A instalação temporária de cidadãos estrangeiros não admitidos em Portugal ou em processo de afastamento do território nacional. Lisboa: Provedoria de Justiça, 2011.

SHARMA, Nandita. Travel Agency: A Critique of Anti-Trafficking Campaigns. Refuge, v. 21, n. 3, 2003, p. 53-65.

STUMPF, Juliet P. The justice of crimmigration law and the security of home. In UGELVIK, Synnøve; HUDSON, Barbara (eds.). Justice and security in the 21st century: risks, rights and the rule of Law. New York: Routledge, 2012, p. 43-63.

WEBER, Serge. D'un Rideau de Fer à L'Autre: Schengen et la Discrimination dans I'Accès à la Mobilité Migratoire. Géocarrefour, v. 84, n. 3, 2009, p. 163-171.

WOMEN'S LINK WORLDWIDE. Mujeres en los centros de internamiento de extranjeros (CIE): realidades entre rejas. Disponível em: <http://www. womenslinkworldwide.org/>. Acesso em: 02.03.2013.

Recebido para publicação em 11.01.2016

Aceito para publicação em 21.03.2016

Received for publication in January $11^{\text {th }}, 2016$

Accepted for publication in March 215t, 2016

ISSN impresso 1980-8585

ISSN eletrônico 2237-9843

http://dx.doi.org/10.1590/1980-85852503880004811 